\title{
Produções cinematográficas e adventismo: uma análise dos conflitos e aproximações a partir da Revista Adventista
}

\author{
Cinematographic productions and adventism: an analysis of conflicts and \\ approximations from the Revista Adventista
}

\section{Producciones cinematográficas y el adventismo: un análisis de los conflictos y aproximaciones a partir de la Revista Adventista}

\author{
Rodrigo Follis ${ }^{1}$ \\ Victor Sotero ${ }^{2}$
}

\begin{abstract}
Resumo
O presente artigo analisa a abordagem da Revista Adventista quanto ao consumo e produção de filmes. Foram verificadas as termologias filmografia, cinematografia, documentário, curta-metragem, longa metragem e filme dentro do periódico. As mais de 1.000 menções catalogadas foram distribuídas em duas tabelas, a primeira (quantitativa) dividiu as citações encontradas por década e a segunda (qualitativa) abordou como as diferentes passagens se encaixaram em grupos de inferência. Os dois esquemas passaram por observação, exame e estudo analítico. $\mathrm{O}$ objetivo foi explorar o desenvolvimento do pensamento quanto a produções cinematográficas dentro da principal revista dessa denominação religiosa. Essa apuração pretende construir a relação do adventismo com os filmes dentro do histórico de publicações do periódico, ao acentuar os processos de construção do pensamento frente ao tema ao longo dos anos. A investigação se deu a partir de um estudo documental baseado na pesquisa metodológica de Appolinário (2009), Bardin (2011), Follis (2017) e Jorge; Barros (2009).
\end{abstract}

Palavras-chave: Adventistas. Revista Adventista. Filmes. Comunicação.

\begin{abstract}
Abastract
This article analyzes Revista Advetnista approach to movie consumption and production. We verified the termologies filmography, cinematography, documentary, short film, feature film and film within the periodical. The more than 1,000 cataloged mentions were distributed in a first table (quantitative) that divided the citations found by decade and in a second table (qualitative) that the different passages fit into inference groups. The two schemes went through observation, examination, and study. The goal was to explore the development of Adventist thinking about film productions within the corporation's major magazine. This investigation aims to build the relationship between Adventism and the films within the journal's history of publications. To accentuate the processes of construction of the thought before the theme over the years. The research was based on a documentary study based on the methodological research of Appolinário (2009), Bardin (2011), Autor (2017) and Jorge; Barros (2009).
\end{abstract}

Keywords: Adventists. Adventist Review. Film. Communication.

Resumen: El presente artículo analiza como la Revista Adventista aborda el consumo y la producción de películas. Se verifico la terminología filmográfica, cinematográfica, documental, cortometraje, largometraje y película dentro de la revista. Las más de 1.000 menciones catalogadas fueron distribuidas

\footnotetext{
${ }^{1}$ Doutor em Ciências da Religião e Mestre em Comunicação Social pela Universidade Metodista de São Paulo. Professor no Centro Universitário Adventista de São Paulo (Unasp) e diretor da Unaspress. E-mail: rodrigo.follis@unasp.edu.br

${ }^{2}$ Bacharelando em Comunicação Social e em Teologia no Centro Universitário Adventista de São Paulo (Unasp). E-mail: victor.sootero@hotmail.com
}

Comun. \& Inf., Goiânia, GO, v. 21, n. 3, p. 3-17, out./dez. 2018. 
en una primera tabla (cuantitativa) que dividió las citaciones encontradas por décadas, y en una segunda tabla (cualitativa) los diferentes pasajes que se encajaron en grupos de inferencia. Los dos esquemas fueron pasados por observación, examen y estudio. El objetivo es explorar el desarrollo del pensamiento adventista en cuanto a producciones cinematográficas dentro de la principal revista de la corporación. Esta pesquisa pretende construir la relación del adventismo y las películas dentro del historial de publicaciones de la revista. Acentuar los procesos de construcción del pensamiento frente al tema a lo largo de los años. La investigación se dio a partir de un estudio documental basado en la investigación metodológica de Appolinário (2009), Bardin (2011), Autor (2017) y Jorge; Barros (2009).

Palabras-clave: Adventistas. Revista Adventista. Películas. Comunicación.

\section{INTRODUÇÃ̃O ${ }^{3}$}

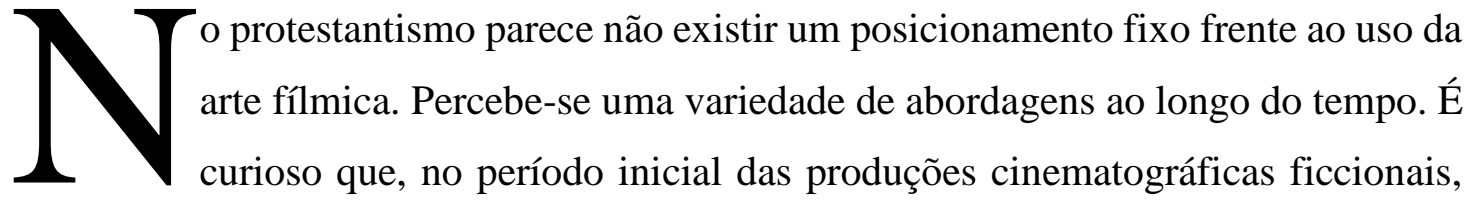
uma parcela considerável dos filmes eram de temáticas cristãs. Mas, mesmo em meio a um contexto favorável, erguiam-se aqueles que distanciavam a religião cristã dessa nova expressão artística. O começo do século 20 marcou um crescimento exponencial da filmografia, em contrapartida, também se obteve o afastamento de grande parte das religiões cristãs da nova arte (NASCIMENTO; CRUZ, 2017). Foi também nesse período que cresceu certo preconceito e desconfiança por parte da sociedade em geral para com as produções fílmicas. Se aguçou uma preocupação em relação à potencial combinação de imagens e sons. Esse paradoxo pode ser percebido na argumentação de Hagemeyer (2012, p. 17), para quem:

De um extremo a outro, nossa reação pode variar entre o deslumbramento diante das potencialidades que abrem para o aprendizado humano, ou o terror diante das implicações que esse tipo de artifício fantasioso poderia ter no entorpecimento das consciências. Ao longo do século 20, essas duas posturas marcaram os debates acadêmicos em torno do significado da produção audiovisual na sociedade contemporânea.

Nos EUA, de maneira especial entre os anos de 1950 até 1970, se consolidou a opinião pública que as artes fílmicas tinham por trás de seus discursos e produções uma ênfase na “manipulação mental”. Essa teorização repercutia a escola de pensamento que atribuía à mídia um poder ilimitado frente aos seus espectadores. Os filmes e a TV foram acusados como moldadores de comportamentos, inibidores da vontade e construtores de hábitos sociais.

\footnotetext{
${ }^{3}$ Toda essa primeira seção histórica, fora da Revista Adventista, ancora bastante suas bases em discussões ocorridas em Kanyat (2017), Nascimento e Cruz (2017) e Novaes (2017).
}

Comun. \& Inf., Goiânia, GO, v. 21, n. 3, p. 3-17, out./dez. 2018. 
Circundado por tais percepções, o ser humano foi considerado refém da arte audiovisual e da influência midiática (KANYAT, 2017).

Embora convivendo com essa elevada polarização, algumas produções fílmicas da década de 1950 resgataram o público protestante. Como exemplo o filme Os Dez Mandamentos (1956), de Cecil B. DeMille, teve grande repercussão, ganhando prêmios internacionais. A separação entre crentes e a $7^{\circ}$ arte, com o passar dos anos, foi se diluindo, e a relação entre eles pendeu novamente para um otimismo. Hoje o pensamento é mais ameno, pois, como lembra o roteirista cristão Briam Godawa (2004, p. 10), muitos acreditam que "filmes são como sermões narrativos". O que possibilitou a existência de produções de filmes cristãos que fazem grande sucesso e têm grande propagação comercial. Obras recentes e que tiveram êxito como Deus não está morto (2014), O quarto de guerra (2015) e Ressureição (2016) são alguns dos exemplos que demostram o atual investimento em produções cinematográficas pelos e para os religiosos.

Dentro dessa linha, este artigo se preocupa com a maneira com que a Igreja Adventista do Sétimo Dia (IASD), como instituição, se relaciona/relacionou com tais produções culturais. Cremos que a IASD e a $7^{\circ}$ arte possuem uma relação de constante ambivalência. Como vivido pelo protestantismo, não há uma única “posição adventista” a respeito do tema, mas é possível traçar claras correntes e períodos de pensamento. Como uma denominação religiosa não está imune às mudanças culturais que a circundam, as opiniões estão propícias a mudar. Assim, vemos que a postura histórica adventista a esse respeito, com o passar dos anos, viveu algumas tensões modificadoras que conseguimos traçar no presente artigo e foi observada também em outros trabalhos anteriores ao nosso (KANYAT, 2017; NASCIMENTO; CRUZ, 2017; ver FOLLIS, 2017).

O fato real é que, na Igreja Adventista da América do Sul, a elaboração de filmes é algo recente. Kanyat (2017) explica que "apesar da produção de ficção televisiva estar nas primeiras páginas da história audiovisual da IASD, na América do Sul ela é um macro-gênero pouco utilizado". A obra mais antiga que se tem conhecimento é a Vitória Final (1968), uma médiametragem argentina. Apenas muito tempo depois que vimos ser lançado a obra independente $A$ Última Batalha (2005), a primeira longa-metragem com mensagem adventista no Brasil. Adotada pela denominação apenas após sua produção estar totalmente finalizada e pronta para o lançamento. Depois desse fomento inicial a filmes independentes, produções projetadas integralmente pela igreja começaram a aparecer, mas apenas a partir de 2012.

O presente artigo terá as considerações acima como pressupostos, caminhando para abordar uma questão mais específica: qual o desenvolvimento do pensamento adventista quanto a produções cinematográficas pode ser encontrado na Revista Adventista? Intencionamos, com

Comun. \& Inf., Goiânia, GO, v. 21, n. 3, p. 3-17, out./dez. 2018. 
essa problemática, analisar parte do desenvolvimento institucional da IASD brasileira quanto a sétima arte, encontrada em seu principal periódico. Para tanto, o artigo tem três objetivos: 1) desenvolver um arcabouço metodológico para a presente pesquisa; 2) categorizar os dados sobre filme, curta-metragem, longa-metragem e documentários encontrados na Revista Adventista; 3 ) iniciar uma análise dos resultados obtidos na categorização.

\section{METODOLOGIA}

A presente pesquisa é caracterizada como documental, pois se utiliza de uma fonte bem delimitada de estudo. A partir da análise de conteúdo, entendemos documento como uma "informação registrada, formando uma unidade, que possa servir para consulta, estudo ou prova" (APPOLINÁRIO, 2009, p. 67). A escolha dessa metodologia se embasou na estrutura e construção crítica proposta por Follis (2017). O corpus escolhido é a Revista Adventista, nela a busca foi direcionada por um conjunto de palavras-chave que serviram de material a ser analisado, não se tratando assim de um método probabilístico, mas censitário. As expressões: filme, filmografia, produção de filmes, cinematografia, curta-metragem, longa-metragem e documentários, quanto ao seu aparecimento no conjunto de revistas, foram citadas numa tabela quantitativa, os quais posteriormente passaram por observação qualitativa. Assim, a metodologia começa quantitativa e baseada na análise de conteúdo, mas passa para uma análise de discursos qualitativa em sua segunda fase.

Para chegar à constituição das tabelas, o artigo trouxe como referência a metodologia de Bardin (2011) quanto a uma organização da análise por três fases: a pré-análise; $a$ exploração do material; o tratamento dos resultados. Na primeira fase foi encolhido os documentos a serem submetidos a análise, a estipulação de hipóteses e objetivos, e a formulação de indicadores que embasem a interpretação final. Logo em seguida elaborou-se operações de codificação, decomposição e enumeração, em função das regras anteriormente fundamentadas. E na última fase os resultados brutos tornaram-se material com fins conclusivos, de maneira a serem significativos e válidos.

Foi feito uso do acervo periódico da Revista Adventista pelo site

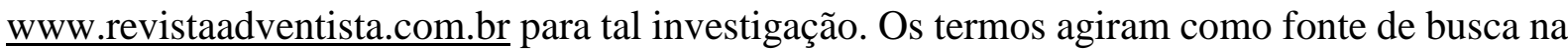
plataforma durante o estudo para a construção de tabelas quantitativas e qualitativas. Através do site, de maneira livre e prática, acharam-se os resultados desejados. Por exemplo, ao somar todas as aparições da expressão "fillme" nas revistas (1906-2017), foram encontradas 1.111 citações. Passaram pelo mesmo processo todas as outras palavras-chaves pré-selecionadas, 


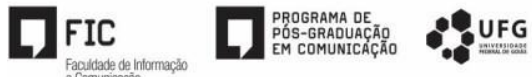

sendo cada uma delas catalogada e analisada. A plataforma online utilizada nesta pesquisa é mantida pela Casa Publicadora Brasileira (CPB), que por sua vez é editora oficial da IASD no Brasil e responsável pelo periódico em questão. A Revista Adventista, periódico de larga importância da instituição no país, é publicada por interruptos 111 anos (de 1906 até os dias de hoje).

A catalogação, como mencionado anteriormente, ocorreu por aparição dos termos préestabelecidos. Em algumas matérias apareceram mais de uma citação, chegando por exemplo a 14 em uma das páginas analisadas. Portanto, as considerações seguiram cada uma a partir de sua lógica direta, pois era de interesse ver todas as vertentes e não apenas a quantidade de citações, seguindo o pensamento de Flick (2009). Independendo da seção em que se encontrava o texto nos periódicos, foram todos ponderados de igual modo perante a investigação, não se separando por editorias ou gêneros jornalísticos. Importando o histórico de publicação e valendo-se apenas do número de aparição por ano, produziu-se assim as tabelas quantitativas.

Cada expressão catalogada passou por uma nova categorização, um "trabalho de classificação e reagrupamento das unidades de registro em número reduzido de categorias" (JORGE; BARROS, 2009, p. 298). Para tanto, uma nova tabela de análises foi criada. Pela quantidade de páginas e aparições estudadas a tabela desposou em décadas, tornando mais simples e clara a visualização e percepção das tendências globais. O período pesquisado vai desde a primeira edição do periódico, de janeiro de 1906, até a última edição anexada no momento da pesquisa ao acervo online (julho de 2017). Considerou-se 1.277 aparições das palavras-chaves pré-selecionadas, distribuídas nas mais de 1.300 edições produzidas no intervalo de tempo estabelecido para análise. O objetivo foi incluir um grande período histórico para obter uma grande variedade de tendências dispostas ao logo dos anos, quanto ao uso de filmes e da produção do mesmo na instituição por trás da revista.

É importante acentuar que se escolheram apenas algumas citações retiradas da revista para serem analisadas de maneira mais qualitativa no presente artigo, as quais acreditamos darem um bom vislumbre das tendências e ondulações encontradas. Como o número de possibilidades e discursos encontrados foram muitos, escolheu-se assim as mais representativas das tendências, categorias e pensamentos achados. Diferente da construção das tabelas, que contemplaram todas as aparições de cada categoria e termo, não foi proposto mencionar o total de citações localizadas.

A categorização construída nesta investigação abre portas para estudos ainda mais detalhados, podendo-se valer de todas as citações, analisando cada uma delas minunciosamente, considerando o período histórico, social e cultural que o texto fora construído e escrevendo 
conclusões por década sobre a temática. Devido ao espaço restrito, o presente artigo delimitouse a apresentar um quadro geral das tendências mais intensas relatadas nas tabelas analíticas e analisar apenas uma vertente específica quanto ao desenvolvimento missionário da IASD como forma de modificações das tendências

Salienta-se que a presente pesquisa presou pela imagem dos autores das reportagens, entrevistas e artigos encontrados na Revista Adventista, ocultando-se, assim, qualquer menção a eles no presente trabalho. Essa escolha se deu por considerar o material como fonte/objeto de apuração, e não, como referência documental primaria. O que em nada tira a credibilidade da pesquisa, pois os pontos focais permaneceram, um exame do conteúdo e tendências do periódico foi construído e respeitou-se o momento histórico e linguístico dos documentos.

\section{A NARRATIVA DA IASD SOBRE PRODUÇÕES FÍLMICAS}

A revista tem publicações a partir de 1906 e desde 1928 é possível perceber menções a sétima arte, com o passar das décadas a quantidade de citações sobem (tabela 1), o que ocorre de maneira proporcional, acreditamos, com o aumento da adoção dos meios comunicacionais pela sociedade e também com o aumento das páginas do periódico e sua evolução editorial (FOLLIS, 2017). O periódico dá bastante ênfase nos meios de comunicação. Ele não deixa de mencionar nenhum meio, observa-se textos sobre a rádio, televisão, internet, entre outras tecnologias contemporâneas. Buscando se posicionar sobre cada uma dessas mídias, a revista ao discorrer das edições faz alusões positivas, negativas, otimistas e até reprováveis das mesmas. Nisso, já foi percebido que durante os últimos 90 anos, de década em década, o posicionamento da IASD quanto a visualização e produção de filmes foi tencionado, em algumas décadas drasticamente e em outras suavemente (tabela 2).

Na tabela 1, verifica-se que nas últimas duas décadas (2000-2017) se têm mais citações do que nas décadas 1980 e 1990 justas. O que indica que o movimento se posiciona, cada vez mais, frente a utilização e visualização desde meio popular de larga escala dentro da sociedade global. E essa é apenas uma das muitas conclusões que se pode tirar depois da construção e estudo quantitativo da tabela elencada a seguir. 
Tabela 1 - Quantificação das expressões referentes a "produções cinematográficas" na Revista Adventista (1906-2017)

\begin{tabular}{|c|c|c|c|c|c|c|c|c|c|c|c|c|c|}
\hline Termos & 1906 & 1910 & 1920 & 1930 & 1940 & 1950 & 1960 & 1970 & 1980 & 1990 & 2000 & 2017 & Total \\
\hline Filmografia & 0 & 0 & 0 & 0 & 0 & 0 & 0 & 0 & 0 & 0 & 0 & 0 & 0 \\
\hline Cinematografia & 0 & 0 & 0 & 0 & 5 & 2 & 4 & 8 & 1 & 4 & 6 & 10 & 40 \\
\hline Documentário & 0 & 0 & 0 & 0 & 1 & 3 & 6 & 7 & 11 & 7 & 19 & 51 & 105 \\
\hline Curta-metragem & 0 & 0 & 0 & 0 & 0 & 0 & 0 & 0 & 0 & 0 & 0 & 10 & 10 \\
\hline Longa-metragem & 0 & 0 & 0 & 0 & 0 & 0 & 0 & 0 & 0 & 0 & 4 & 7 & 11 \\
\hline Filme & 0 & 0 & 2 & 6 & 65 & 113 & 223 & 207 & 144 & 97 & 102 & 152 & 1.111 \\
\hline
\end{tabular}

Fonte: Elaborada pelos autores.

A primeira citação sobre o tema foi em Agosto de 1928 (p. 10) e resume uma notícia sobre um terremoto que atingiu o México. Possivelmente fez menção ao incidente que aconteceu em 7 de junho do mesmo ano da publicação, de abalo sísmico de 8,0 na escala de magnitude daquele momento. Na notícia diz que um grupo de pessoas estava assistindo a um filme sobre a vida de Jesus no cinema da cidade quando foram surpreendidos pelo terremoto. A matéria ainda explicou que Jesus estava sendo crucificado no filme, e havia cenas de relâmpagos e trovões e terremoto, algo que por coincidência estava acontecendo de fato fora da sala cinematográfica, causando grande pânico naqueles telespectadores. Mas não se fez mais do que referência ao filme, ao local ou a tal hábito como ação durante o fato noticiado, aqui tem-se apenas um relato histórico usando filmes como base da notícia religiosa. Um posicionamento e discurso sobre o tema só aconteceu 13 anos depois.

A edição de julho de 1941 (p. 28 e 29) veio com o primeiro posicionamento da IASD sobre assistir as películas. Não ocorreu num formato textual noticioso ou de entrevista, mas, sim, através de uma história fictícia que retrata o diálogo de dois colegas, sendo um deles adventista do sétimo dia e a outro (James) não. Um diálogo no qual praticamente o adventista fala e James questiona a posição do colega com algumas poucas perguntas durante toda a conversa. Os discursos dos dois convergem quanto ao posicionamento sobre idas a teatros, cinemas e assistir filmes. $\mathrm{O}$ texto em questão chamou a atenção por ser o primeiro a trazer um posicionamento da instituição, e ser o início das tendências da revista. Além, claro, do tom literário do texto, o que mostra um apreço por histórias, mas talvez não pela imagem, como argumentaremos mais adiante. Abaixo, descreve-se um trecho do texto original:

- Olhe, Donaldo, compreendo porque vocês adventistas do sétimo dia não fumam nem bebem. $\hat{E}$, naturalmente, por serem esses hábitos imundos e prejudiciais; mas não entendo porque não vão ao cinema! Que mal há em assistir a um filme sensacional, emotivo, de vez em quando? [...]

- Uma pergunta de cada vez! [...]. Mas, para responder mais detalhadamente a sua pergunta, permita-me fazer-lhe outra: por que vai você ao cinema? 
- Vejamos — oh, vou em busca de recreação ...

- Recreação? Ora, Jaime, não sabe você a diferença entre diversão e recreação? Assistir a um filme não é recreação; é diversão. [...]

- Pois bem; o que há então de mal em ver um filme para divertir-se?

- Em primeiro lugar, Jaime, não é a espécie correta de divertimento; não eleva o espírito; não promove ideais boas, puras e saudáveis. Ao contrário, contribuem para derribar as normas morais, introduzindo no cérebro pensamentos impuros. Pinta o amor de maneira a fazer com que Deus desaprove os produtores dessa impudência. Exerce sobre cada espectador poderosa influência maléfica. ${ }^{4}$

A observação acima mostra a posição clara do periódico no momento histórico no qual a maior parte dos protestantes também acabam por ignorar os filmes como objetos que os crentes deveriam usar (HAGEMEYER, 2012). Em 1937, a Assembleia Geral da Igreja Adventista do Sétimo Dia produziu um documento situando-se quanto ao tema. No oficio não se definiu o "local" do cinema como perigoso em si, mas basicamente relacionava-o como instituição veiculadora de produtos - esses, sim - perniciosos ou anticristãos (NOVAES, 2016). Nos anos 1940, portanto, o cinema não era assimilado a um ambiente pecaminoso e alienador, mas apenas como um local propagador de filmes, os quais, por sua vez, em seu conteúdo, seriam incoerentes para os adventistas.

Hagemeyer (2012) explicou que na década de 1940 houve um combate de intelectuais, principalmente os da teoria crítica, quanto a adesão as rádios comerciais e as produções hollywoodianas. Nas palavras de Hagemeyer (2012), a crença era de que "o cinema não parecia oferecer nada mais que ilusões", reforçando a ideia que o problema estava nos projetos cinematográficos. Como nos lembra Novaes (2017, p. 48), “embora o adventismo mantenha hoje em vários países um posicionamento de que o local de cinema é danoso e não recomendável, seja por questões tecnológicas ou de ambiente social, essa compreensão não era comum até o final dos anos 1940". Por isso, nota-se que no período em que a construção do texto delongado acima (1930-1949) à ênfase da instituição adventista estava no afastamento das produções de "pensamentos impuros" e não nos locais de exibição em si.

\footnotetext{
${ }^{4}$ Optamos por deixar os textos da Revista Adventista tal como fora publicado originalmente, com as regras gramaticais daquele momento histórico, não o adaptando para o nosso momento histórico-gramatical.
} 
Tabela 2 - Categorização das expressões referentes a "produções cinematográficas" na Revista Adventista (1906-2017)

\begin{tabular}{|c|c|c|c|c|c|c|c|c|c|c|c|c|c|}
\hline Termos & 1906 & 1910 & 1920 & 1930 & 1940 & 1950 & 1960 & 1970 & 1980 & 1990 & 2000 & 2017 & Total \\
\hline Mídia influente & 0 & 0 & 0 & 1 & 8 & 20 & 17 & 12 & 17 & 10 & 23 & 25 & 133 \\
\hline $\begin{array}{l}\text { Assistir filmes } \\
\text { como ato ruim }\end{array}$ & 0 & 0 & 0 & 0 & 17 & 15 & 24 & 18 & 12 & 33 & 16 & 35 & 170 \\
\hline $\begin{array}{c}\text { Uso positivo } \\
\text { para educação }\end{array}$ & 0 & 0 & 1 & 1 & 14 & 22 & 96 & 91 & 75 & 40 & 31 & 48 & 419 \\
\hline Avanço da arte & 0 & 0 & 1 & 0 & 4 & 7 & 12 & 5 & 7 & 2 & 3 & 6 & 47 \\
\hline $\begin{array}{c}\text { Filmes não } \\
\text { devem ser } \\
\text { usados }\end{array}$ & 0 & 0 & 0 & 2 & 0 & 0 & 1 & 0 & 0 & 0 & 1 & 0 & 4 \\
\hline $\begin{array}{l}\text { Usar com fins } \\
\text { evangelísticos }\end{array}$ & 0 & 0 & 0 & 2 & 28 & 50 & 81 & 96 & 45 & 22 & 53 & 116 & 493 \\
\hline $\begin{array}{l}\text { Descontração } \\
\text { familiar }\end{array}$ & 0 & 0 & 0 & 0 & 0 & 2 & 1 & 0 & 0 & 0 & 1 & 0 & 4 \\
\hline
\end{tabular}

Fonte: Elaborada pelos autores.

A Revista Adventista acompanha a cinematografia desde seu primórdio no Brasil. Na parte final da década de 1920 encontram-se as primeiras inferências ao assunto, e desde então não se parou mais. Percebeu-se facilmente, através da tabela 2, que as citações sobre o tema aumentaram com o passar dos anos, e diferentes posicionamentos quanto o assunto também se acentuaram. O que se constatou, com mais intensidade, foram menções que indicaram que a sétima arte é um grande instrumento propagador da mensagem da IASD, que os filmes são usados com fins evangelísticos pela instituição. Exemplos desta declaração elenca-se nos textos de janeiro de 1942 (p. 12), novembro de 1953 (p. 9), setembro de 1969 (p. 9), e julho de 2010 (p. 33). Hoje o adventismo utiliza largamente a arte fílmica como divulgação de sua mensagem, como podemos ver em lançamentos recentes de filmes produzidos pela denominação (o site Feliz7Play é uma boa mostra disso), mas, o que ocorre desde cedo ainda existe atualmente: há uma proibição da ida ao cinema e um desgosto de filmes de fora dos ambientes da instituição.

Podemos argumentar, seguindo a lógica de trabalhos anteriores (FOLLIS, 2017), que essa realidade existe em grande parte devido às ênfases quanto à evangelização dadas pelo movimento adventista ao longo dos anos, pois elas acabam por justificar os meios utilizados (FOLLIS, 2017). Filmes podem ser usados, desde que visto dentro da lógica refletida no diálogo de James e Donaldo elencado anteriormente: é recreação (ou seja, é educativo), então está tudo bem. É diversão (ou seja, só entretenimento), então não pode. Se for evangelização (entendida como parte da recreação), melhor ainda.

Nessa mesma linha, em uma publicação de novembro de 1954 (p. 27) encontrou-se um texto reflexivo, voltado aos pais adventistas quanto aos "efeitos" e "verdades" dos filmes e

\footnotetext{
${ }^{5}$ Na presente tabela colocamos os achados da Tabela 1 catalogados através de uma análise qualitativa, que busca organizar os achados a partir de categorias positivas, negativas ou neutras, as quais foram criadas por nós a partir dos textos encontrados.
}

Comun. \& Inf., Goiânia, GO, v. 21, n. 3, p. 3-17, out./dez. 2018. 


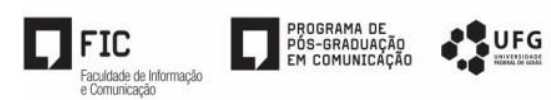

sobre o cinema - quando nessa matéria situa-se a expressão cinema, o texto faz menção as produções audiovisuais em si. A publicação não indica quem a escreveu a matéria, mas o autor em um dos parágrafos enfatiza que o filme "prejudica para sempre o caráter, porque suscita um excesso de emoções, sem dar aos assistentes a oportunidade de traduzi-las em ação. Noutras palavras, sobrecarrega e esgota a reserva emocional, lesando nosso delicado mundo psíquico".

Posto essa citação de objeção e as demais de exceção (com fins evangelísticos) deixadas acima, conclui-se que de um lado da moeda acha-se oposição à produção cinematográfica, enquanto do outro lado, percebe-se uma apropriação desses meios em alguns casos específicos.

O olhar da organização para com as obras cinematográficas, dentro do periódico examinado por este artigo, viveu (1906-2017) um ritmo resiliente, mas pouco linear. Foi possível, dentro disso, encontrar tanto alusões de resistência como resignação. À vista disto, duas categorias da tabela 2 precisam ser melhores analisadas. E para melhor explanar essa questão, duas passagens de matérias da década de 1970 serão perscrutadas. A primeira é de novembro de 1978 (p. 23), quando se publica um texto noticiário sobre a semana da arte do Instituto Adventista de Ensino, hoje Centro Universitário Adventista de São Paulo (Unasp) -, uma semana na qual a instituição enfatizou atividades culturais que envolviam os alunos e professores da corporação. A matéria informou a programação do final de semana do evento, e sinalizou que no domingo os alunos, professores e comunidade foram convidas para assistir ao filme Branca de Neve e os Sete Anões, uma proposta que chamou a atenção e interesse de muitos, e "encantou a plateia por sua beleza artística e também por suas lições morais".

Três edições posteriores a mencionada acima, encontramos uma outra matéria sobre o tema estudado neste artigo, no entanto de um posicionamento diferente, sendo desta vez resistente aos filmes. A matéria Influências desmoralizantes, de fevereiro de 1979 (p. 38), enfatiza os "perigos da vida moderna" e como os cristãos devem agir frente a tal sofisticação social:

\footnotetext{
Alguns filmes [...] foram feitos, cujos resultados não se podem medir, encenam cenas altamente elaboradas, que excitam a imaginação e despertam uma corrente de pensamentos repleta de perigos, especialmente para os jovens. As cenas fantásticas apresentadas nesses filmes são repetidamente vividas na imaginação de moços e moças, especialmente dos adolescentes. A mente é saturada pela ficção e como resultado não podemos esperar que se desenvolva caráter cristão nos jovens que presenciam tais filmes.
}

O contrate encontrado nessas matérias são vistas em dois filósofos famosos, mesmo em realidades e contextos diferentes aos do periódico analisado aqui, eles geraram interpretações com relação à produção de imagens e pinturas, estamos falando de Platão (2006) e Aristóteles 
(2000). Enquanto Platão visualiza a "arte de imitar" com olhos catastróficos e enfatizava o "perigo da manipulação", Aristóteles apreciava as imagens, pois se elas nos proporcionam "deleite, é porque a quem contempla sucede aprender a identificar cada uma delas".

Essas questões levantam perguntas interessantes e necessárias para o entendimento axiológico do campo de estudo das relações entre mídia e religião. A articulação desses assuntos tem relevância direta na discussão aqui realizada. É preciso olhar para os resultados da tabela 1 e tabela 2 e os analisar de maneira ainda mais sociológica e menos descritiva. Faremos isso logo a seguir, mas ainda essa discussão pode e deve ser ampliada a partir de outras perspectivas, em trabalhos futuros, pois aqui abordaremos apenas um início, despertando a academia para a importância e a riqueza de se pesquisar as relações entre os adventistas e a mídia, principalmente em sua relação com a sétima arte, algo que duas teses recentes, citadas ao longo do presente texto, apenas começaram a fazer (NOVAES, 2016; FOLLIS, 2017). Mas já é possível arriscar alguns caminhos a serem seguidos, e é isso que faremos na seção a seguir.

\section{CAMINHOS A SEREM PENSADOS: ADVENTISMO, CONVERSÃO E MÍDIA}

Na edição de janeiro de 1999 (p. 14-15) a revista faz um balanço sobre os programas e investimentos realizados nas diversas frentes comunicacionais. Um dos principais acontecimentos naquele momento era a consolidação das semanas especiais via satélite. Nesses casos, um pregador é escolhido pela igreja e uma semana especial é realizada com ele, transmitida ao vivo de uma igreja para todo o Brasil. O próprio nome da notícia já deixa claro a importância desse evento: "Mensagem no ar: pregação via satélite ultrapassa fronteiras e converte pessoas no Brasil e no mundo". No decorrer do texto, fica mais claro uma crítica que surge com mais força nos últimos anos quanto ao uso dos meios comunicacionais, não se apregoa mais que eles seriam manipuladores e influenciadores determinantes para as conversões. Ainda se acredita no uso de tais instrumentos, principalmente devido a sua massificação extraordinária e não tanto a um poder mágico que eles teriam como pregadores unanimes. A revista coloca que o

rádio e a TV não são instrumentos de conversão. Esse é o papel do Espírito Santo por meio dos membros da igreja. Os meios de comunicação estão aí para despertar interesse e criar possibilidades. Cabe à igreja a colheita. Sem o envolvimento dos membros, todo o trabalho é perdido. Fica no ar. Outros colhem. 


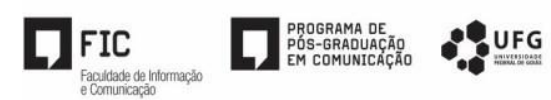

Nas mesmas páginas, um pequeno box discute criticamente as notícias que ali se colocam. Nos chamam a atenção a leitura mais madura dos meios comunicacionais dentro de suas potencialidades. Sua nota se intitula "Muitos meios, um fim", e argumenta que o surgimento de novas formas comunicacionais não determina o fim das antigas. Para o articulista, o rádio não foi a morte do jornal impresso, a televisão não tomou o lugar em definitivo do rádio e a internet, que naquele momento apenas iniciava, não seria a responsável pelo fim dos demais meios comunicacionais. A se pensar que essa leitura fora feita em 1999, é interessante notar que muito do que ali foi analisado realmente se concretizou, não existindo o fim de nenhum desses meios na atualidade, mas, de certa forma, todos eles sofreram mudanças estruturais e paradigmáticas profundas, mudando sua própria lógica e funcionamento. Por fim, o autor conclui seu argumento dizendo que "na convivência pacífica entre os diferentes meios, o fim último - salvar - é potencialmente favorecido".

Apesar das importantes ressalvas levantadas, aqui também se caminha na direção do padrão encontrado durante todos os períodos da Revista Adventista, tal como já argumentado anteriormente: não importam os meios, pois a memória fundante de evangelização acaba por ser mais importante do que eles. Assim, cabe argumentarmos que, para o adventismo, o destino manifesto de sua pregação continua vivo e acaba por ser o principal articulador de sua memória, não importando a época ou o meio técnico utilizado. Já desenvolvemos trabalhos anteriores sobre essa relação entre adventismo, memória e mídia (FOLLIS, 2017), aqui nos importa problematizar e elencar de maneira mais precisa a questão dos filmes nessa relação dialógica.

É importante notar que os filmes, diferente da televisão, continuaram a ser visto como algo a ser evitado pelos adventistas em muitos momentos. Em uma reportagem em janeiro de 1945 (p. 5-6), acusa-se esse meio comunicacional de ser "o maior inimigo da civilização, pior do que o comércio de licores". E que a "única regra segura para o cristão é buscar recreação que o seja [boa] - beneficie a saúde física, e fortaleça a sua espiritualidade”. O que torna essa crítica mais interessante é que na mesma página se felicita o rádio, o qual teve em seu começo, o mesmo tratamento que vemos destinado ao cinema. Nas palavras da revista:

Entre os muitos inventos desta geração, está o rádio, o inigualável meio de atingir multidões na proclamação da tríplice mensagem, e Deus despertou aos que digerem a obra, que êste meio não poderia ser pôsto à margem. Como com quase tôdas as invenções dêste século Satanaz procura tirar proveito para seus intentos, o rádio tornou-se para êle o canal para despejar nos ouvidos dos homens quantidade enorme de irradiações nocivas. Graças a Deus, porém, que no meio dessa obra de perdição, coube à obra de salvar e elevar a humanidade um caminho que deve ser defendido a todo o curso e ampliado o mais possível. O que "A Voz da Profecia" tem realizado, dizem-no bem alto as muitas cartas 
que são enviadas de tôdas as partes do Brasil à direção dêsse trabalho evangélico. [...] Esta obra é divina e nada poderá detê-la. O inimigo das almas tem tentado por tôdas as maneiras afastar a influência benéfica das irradiações adventistas, mas ainda que algumas portas se fecharam muitas se abriram para alargar a pregação da verdade. [...]. Nada, porém, poderá impedir que o mundo seja advertido da breve volta do Salvador amado e almas sinceras abandonem êste mundo de perversidade e sigam a fé de Jesus e Seus mandamentos.

Ao se perceber o rádio como algo a ser celebrado, como o cumprimento de Daniel 12:4, no mesmo contexto em que se acusa o cinema e os filmes, algumas questões podem ser discutidas: a princípio poderíamos pensar que a questão está na disposta entre "a imagem e a literalidade". Em outras palavras, se recusaria esses meios devido ao uso de imagens, em detrimento ao texto. Pelo adventismo ser um movimento livrocentrico, tal como os diversos grupos protestantes que têm na Bíblia sua maior forma de articulação social, essa argumentação pode parecer faz algum sentido. Por outro lado, não cremos ser possível atribuir apenas a ela a causa da recusa de um meio em detrimento ao outro. Pouco tempo depois a própria televisão, imagética, passa a ser utilizada por programas do movimento. O que não ocorre com o cinema e os filmes, existindo críticas a ele mesmo em edições recentes, tais como em dezembro de 1998 (p. 37), janeiro de 1999 (p. 36), janeiro de 2004 (p. 18-19), maio de 2004 (p. 18) etc.

É possível afirmar que a identidade doutrinária adventista acaba por legitimar, no sentido weberiano, os meios comunicacionais, principalmente devido à necessidade de se pregar ao mundo todo de maneira rápida, o que esses meios permitem. Ao mesmo tempo também vemos uma condenação a esses instrumentos, principalmente quando se percebe que eles possam tirar o foco da mensagem adventista e de sua pregação. E como isso seria possível? No histórico encontrado na Revista Adventista, isso ocorreria principalmente através da recusa de programas que não tenham um viés pedagógico (e a recreação, tal como discutida em um exemplo anterior, entraria dentro desse aspecto pedagógico), o que não implica apenas que o crente deveria ver apenas programas cristãos, mas com certeza esses seriam a melhor opção.

Como o cinema/filmes demoram para ser usados como pregação da mensagem, eles demoram a ser legalizados pelo movimento como um meio válido. $\mathrm{O}$ adventismo justifica sua tensão entre recusa e uso dos meios comunicacionais através de sua memória fundante, quanto a importância de sua pregação ser ouvida por todo o mundo (FOLLIS, 2017). Afinal, dentro do adventismo, o objetivo maior sempre será a pregação de sua mensagem, mas a ênfase dela pode ser modificada. Um exemplo disso é a tensão entre a pregação da mensagem se utilizando dos instrumentos comunicacionais e a condenação, nesse mesmo período, desses mesmos meios. Aqui vemos um fruto da abordagem racionalista própria do movimento, que considera o 
entretenimento algo ruim em si e coloca o texto ainda como fonte máxima de conhecimento e aprendizagem. Em resumo, dentro dessa perspectiva, um programa comunicacional será considerado bom apenas se nele encontrarmos questões educacionais. Nesse sentido, os programas da própria denominação sempre ganharam mais predominância do que os demais, afinal, a memória religiosa sempre será combativa e considerará que nenhuma outra fonte de ensino se fará superior a ela.

\section{CONSIDERAÇÕES FINAIS}

A cada década que passa nota-se que a IASD se desperta mais intensamente para a produção cinematográfica como um recurso comunicacional em potencial (NASCIMENTO; CRUZ, 2017). Percebe-se que a instituição, cada vez mais, faz uso desta plataforma como propagadora da sua cosmovisão. Em trabalho anterior (FOLLIS, 2017) argumentamos que a ênfase da corporação está em pregar sua mensagem ao maior número de pessoas possíveis, com diligência e celeridade. Isso é de fácil assimilação ao observar as 493 citações (tabela 2) que fazem inferência a arte fílmica como um meio de difusão do evangelho e que aqui foram analisadas. Utiliza-se da mídia sempre com instrumental pedagógico, fugindo-se da "aparência de entretenimento" que ela possa ter.

Por fim, vale salientar que a Revista Adventista trilha um aprofundamento teológico e comunicacional em relação ao tema, e que por mais que os contras existam, desde as primeiras alusões a arte fílmica verifica-se que sobressaem as menções positivas quanto ao seu uso. $\mathrm{O}$ adventismo adota a cada década uma nítida posição quanto a essas produções e elas se diferem entre si. Não é apenas o caso de se condenar o cinema/filmes ou os aceitar, mas discutir-se os motivos e as razões que devem nos levar a fazer isso ou aquilo. Existem ainda muito para se aprender e analisar quanto a relação entre os adventistas e os filmes. Por isso, esta pesquisa é apenas um prelúdio para estudos futuros que precisam se debruçar nessa discussão que consideramos importante para o campo de estudos da mídia e religião.

\section{Referências}

APPOLINÁRIO, F. Dicionário de metodologia científica: um guia para a produção do conhecimento científico. São Paulo, Atlas, 2009.

ARISTÓTELES. Poética. São Paulo: Nova Cultural, 2000. (Coleção Os Pensadores). 
BAUER, M. Pesquisa qualitativa com texto, imagem e som: um manual prático. São Paulo: Vozes, 2015.

CGODAWA, B. Cinema e fé cristã. Ultimato: São Paulo, 2004.

CORRÊA, W. Análise do conteúdo. In: DUARTE, J.; BARROS, A. (Orgs). Métodos e técnicas de pesquisa em comunicação. São Paulo: Editora Atlas, 2009

CRUZ, B; RIBEIRO, B. O adventismo e os filmes. In: CARMO, F; NOVAES, A. (Orgs). O adventismo e a cultura pop. São Paulo: Editora Unaspress, 2017.

FLICK, U. Introdução à pesquisa qualitativa. São Paulo: Penso, 2008.

FOLLIS, R. Memória, mídia e transmissão religiosa: estudo de caso da Revista Adventista (1906-2010). Tese (Doutorado em Ciências da Religião). Universidade Metodista de São Paulo, São Bernardo do Campo, 2017.

HAGEMEYER, R. História e audiovisual. São Paulo: Autêntica, 2012.

NOVAES, A. O problema adventismo-televisão: uma análise do pensamento adventista sobre a TV a partir da tipologia de H. Richard Nierbuhr em Cristo e cultura. Tese (Doutorado em Ciências da Religião). Pontifício Universidade Católica de São Paulo, São Paulo, 2016.

PLATÃO. A República. São Paulo: Martin Claret, 2006. 